\title{
Intra- versus inter-sexual selection in the dimorphic electric organ discharges of the snoutfish Marcusenius altisambesi (Mormyriformes, Teleostei)
}

\author{
Peter Machnik, Bianca Markowski \& Bernd Kramer ${ }^{1)}$ \\ (Zoologisches Institut der Universität Regensburg, Universitätsstrasse 31, \\ 93040 Regensburg, Germany)
}

(Accepted: 19 January 2010)

\begin{abstract}
Summary
Marcusenius pongolensis (South Africa) and M. altisambesi (Upper Zambezi/Okavango) differ in the sex difference of their electric organ discharges (EODs). It is permanent and graded in the former and seasonally dimorphic in the latter. Four out of six experimental female M. altisambesi gave significantly stronger responses to the long playback EODs of breeding males rather than short EODs, whereas four of seven experimental males responded in the opposite way (with one exception in association time). When re-tested after a year, the female preference for long EODs had vanished. Both sexes discriminated between playback EODs as either long or short (unlike M. pongolensis), with the cutoff between 1420 and $2470 \mu$ s (female EOD average, $350 \mu \mathrm{s}$ ). Exposure to social stimuli from tank neighbours of both sexes did not induce growth of EOD duration in males (unlike M. pongolensis). We suggest that in $M$. altisambesi the sexually dimorphic male EOD has evolved under female (inter-sexual) selection (in M. pongolensis, both inter- and intra-sexual selection); that there is no evidence for male-male competition (intra-sexual selection, present in M. pongolensis); that ecological differences between a floodplain (M. altisambesi) and a more riverine (M. pongolensis) species may be at the origin of the differentiation.
\end{abstract}

Keywords: mating system, female choice, evolutionary plasticity, predator, speciation, selection pressure, playback, electrocommunication.

\footnotetext{
1) Corresponding author's email address: bernd.kramer@biologie.uni-regensburg.de 


\section{Introduction}

Weakly electric fish, such as the bulldog fish Marcusenius altisambesi inhabiting the African rivers Upper Zambezi and Okavango, lead a nocturnal life. During the day they hide in quiet, dark places, and one may find them, often in great numbers, under a sunken or inside a hollow tree, under rocks, or under piles of drift wood. They, thus, escape visually orientated predators such as the tigerfish, Hydrocynus vittatus, the African pike, Hepsetus odoe, and predatory birds such as herons.

At night bulldog fish, like other weakly electric fish, use their electric system while foraging and communicating with conspecifics (for reviews, see Kramer, 1990, 1996; Moller, 1995). Their 'private' information system (for reviews, see Bullock et al., 2005; Ladich et al., 2006; Kramer, 2009) probably made the snoutfish (Mormyridae) the most speciose family of teleosts endemic to Africa. A microsecond-sensory acuity for differences in the waveform of electric organ discharges (EODs) as small as those observed among individuals of the same sex and species was demonstrated by Paintner \& Kramer (2003). It facilitates electrosensory species and mate recognition based on EOD characteristics (Markowski et al., 2008; Feulner et al., 2009), and female choice and critical assessment of male quality (Machnik \& Kramer, 2008a).

However, the EODs of snoutfish may be overheard by predatory catfish that are also electroreceptive and also active at night. It is hypothesized that the evolutionary response of most weakly electric fish lineages (both in South America: the gymnotiforms, and in Africa: the mormyriforms) was a shift to safer high-frequency spectral ranges not utilized by catfish, by adding a second phase of opposite polarity and shortening the originally monopolar EOD, thus keeping out of harm's way (Stoddard, 1999). Catfish ampullary electroreceptor organs are sensitive in the spectral low-frequency range (Lissmann \& Machin, 1963).

Accordingly, amplitude spectra of the biphasic, brief EODs of females and juveniles of $M$. altisambesi are sufficiently high-frequency that they are safe from electrosensory detection by the predatory sharptooth catfish Clarias gariepinus which nevertheless is one of their most successful predators (Merron, 1993). This is because the catfish detect male bulldog EODs at low threshold and long distance (Hanika \& Kramer, 1999, 2000). At sexual maturity male $M$. altisambesi bulldogs increase the duration of their EOD 
pulses by up to $11 \times$ the female average EOD of about $350 \mu$ s (Kramer, 1997a,b), shifting the spectral frequency content sufficiently downward that it becomes detectable by catfish. The size class of bulldogs predominantly eaten by catfish (Merron, 1993) corresponds to the males' turning mature (Kramer, 1997a,b).

What appears as a maladaptive, suicidal EOD, one with a strong spectral low-frequency content, may be the result of sexual selection. Within the genus Marcusenius, the males of other species also tend to show longer EOD pulses than females, e.g., Marcusenius senegalensis and M. pongolensis (Scheffel \& Kramer, 1997; Werneyer \& Kramer, 2002, 2005; Kramer et al., 2007). It is in taxa with increased male trait variability that sexual dimorphism may emerge in some members (Burkhardt \& de la Motte, 1988).

Marcusenius pongolensis and M. altisambesi form part of the M. macrolepidotus species complex and were recognised as distinct, allopatric species only recently (Kramer et al., 2007). In M. pongolensis there is experimental support for both intra-sexual selection (male-male competition; Hanika \& Kramer, 2005, 2008) and inter-sexual selection (female choice; Machnik \& Kramer, 2008a) having shaped the specific kind of EOD sex difference in this species. M. pongolensis males, on turning mature, start to elongate their EOD pulses linearly with fish standard length over life time. This is barely perceptible in the first year, and growth of EOD pulse duration is slow and remains far below the extreme values found in M. altisambesi. The M. pongolensis sex difference contrasts with the sexual dimorphism observed in M. altisambesi where the change from a juvenile EOD to that of a sexually mature male is 'explosive' and reaches its full extent already in the first season. The sex difference in M. pongolensis is permanent and slowly growing whereas in M. altisambesi it is dramatic and limited to the breeding season, after which EOD pulse length recedes to that of females and juveniles (Kramer et al., 2007).

EOD playback experiments have helped analyse the selective forces operating in M. pongolensis. In the present study we used a similar approach to study $M$. altisambesi in an attempt to elucidate the marked evolutionary plasticity of the mating system in two species that were not recognised as distinct until recently. 


\section{Material and methods}

\section{Fish and their care}

We studied samples of Marcusenius altisambesi Kramer et al. 2007 originating from the type locality, that is, Namibia's section of the Upper Zambezi River, East Caprivi Strip, Kalimbeza, $17^{\circ} 32^{\prime} 27.3^{\prime \prime} \mathrm{S}, 24^{\circ} 31^{\prime} 26.2^{\prime \prime} \mathrm{E}$. This is $22-26 \mathrm{~km}$ as the crow flies downstream of Katima Mulilo. Specimens were caught on 21 August 1999 by F.H. van der Bank and B. Kramer and exported to Germany by an overnight flight. Fish were kept in the aquaria of the University of Regensburg in groups of two or three fish per tank $(250 \times 50 \times 50 \mathrm{~cm})$, separated by plastic screen mesh in order to exclude damaging fights but nevertheless to afford social contact. The tanks offered various stones, porous pots and green plants such as Cryptocoryne sp. and Vesicularia sp. as shelter; the L/D cycle was 12:12 h. Experimental observations were made in a separate tank with dimensions $290 \times 70 \times 50 \mathrm{~cm}$ high. Water conductivity and temperature varied between 50-200 $\mu \mathrm{S} / \mathrm{cm}$ and $25 \pm 1{ }^{\circ} \mathrm{C}$ in the holding tanks and were kept nearly constant in the experimental tank at $100 \pm 10 \mu \mathrm{S} / \mathrm{cm}$ and $25.0 \pm 0.2^{\circ} \mathrm{C}$. Fish were fed Chironomus sp. larvae (mostly deep-frozen and freshly thawed, rarely live ones) five times a week.

We used seven males and six females of M. altisambesi (standard length (distance tip of upper jaw to midbase caudal fin, SL) $>12.5 \mathrm{~cm}$ ) as experimental subjects in Test series I, and 10 females (SL 13.7-15.3 cm) and seven males (SL 15.1-17.5 cm) in Test series II (from the same sample of fish). For Test series II we also used a second sample of 17 specimens of $M$. altisambesi (10 females, SL 12.8-14.3 cm; seven males, SL 13.7-15.3 cm) from the Okavango Delta, panhandle region, Guma Lagoon $\left(18^{\circ} 57^{\prime} 46.6^{\prime \prime} \mathrm{S}\right.$, $\left.22^{\circ} 22^{\prime} 25.3^{\prime \prime} \mathrm{E}\right)$, caught by F.H. van der Bank and B. Kramer between 10 and 12 August 2004. All specimens were beyond the minimum size for sexual maturity (of about $40 \%$ of the maximum SL of $30 \mathrm{~cm}$ for males, and somewhat less than $40 \%$ for females; Skelton, 2001; Kramer et al., 2007). Like in many other mormyrid species (Iles, 1960), males are recognised by a kink in the anal fin base which is straight in females (Skelton, 2001; Kramer, 1997a,b). Test series I was conducted from January 2007 to June 2007, Test series II from January 2008 to December 2008.

We included the Okavango specimens in the study because Kramer et al. (2007) could not find sexually dimorphic EODs in males of this popula- 
tion of M. altisambesi in the field on 21-24 January 2001, raising suspicion as to their species identity. This turned out to be groundless: the flood pulse from the Angolan Highlands arrives in the Okavango delta only in March/April (Merron \& Bruton, 1995); additional gene sequence analyses confirmed there was no noticeable differentiation between the two populations (M. Wink, personal communication).

\section{Recording and analysis of EODs}

EODs were recorded by placing a fish between a pair of low-impedance carbon electrodes in a head-to-tail position, with the positive electrode near the head. The output of a grounded differential preamplifier (Electronics Workshop, University of Regensburg; 1-100 $000 \mathrm{~Hz}$, variable gain) was fed into a digital oscilloscope (TDS 420, Tektronix Holland, Heerenveen, The Netherlands, $150 \mathrm{MHz}$ bandwidth, $1 \mathrm{M} \Omega$ input impedance, sampling rate adjusted to $250 \mathrm{kHz}, 11$ bit vertical resolution, 2500 points per sweep). Field recording conditions were similar using battery-powered equipment (Kramer, 1997a).

As with all known EODs in the genus Marcusenius, EODs were essentially biphasic, brief pulses with a head-positive phase followed by a negative one (Kramer, 1996, 1997a,b; Kramer et al., 2007). In contrast to other species within the M. macrolepidotus complex, M. altisambesi female and juvenile EODs started with a very weak, head-negative pre-potential (Kramer, 1997a,b; Kramer et al., 2007).

For EOD waveform analysis we used custom-made routines programmed in the software package Famos of imc company, Berlin. For estimating EOD pulse duration we set threshold at $\pm 2 \%$ of the head-positive peak amplitude (P phase). A pulse started when the baseline rose above $+2 \%$, and it was terminated when the head-negative $\mathrm{N}$ phase rose above $-2 \%$. This was necessary because of the asymptotic start and termination of an EOD pulse. A Fourier transformation routine provided by Famos generated amplitude spectra of single EOD pulses that were centred in an array of $2^{13}$ points, at $50 \mathrm{kHz}$ sampling rate and $0.2 \mathrm{~Hz}$ frequency resolution.

We used the EODs of 12 males recorded in the field during the 'summer' breeding season (early March 1994) for playback stimulation of experimental subjects. The females were gravid with eggs (oocytes stage VI), and the males, when beyond a minimum size of about $12.5 \mathrm{~cm} \mathrm{SL}$, ripe with plenty 


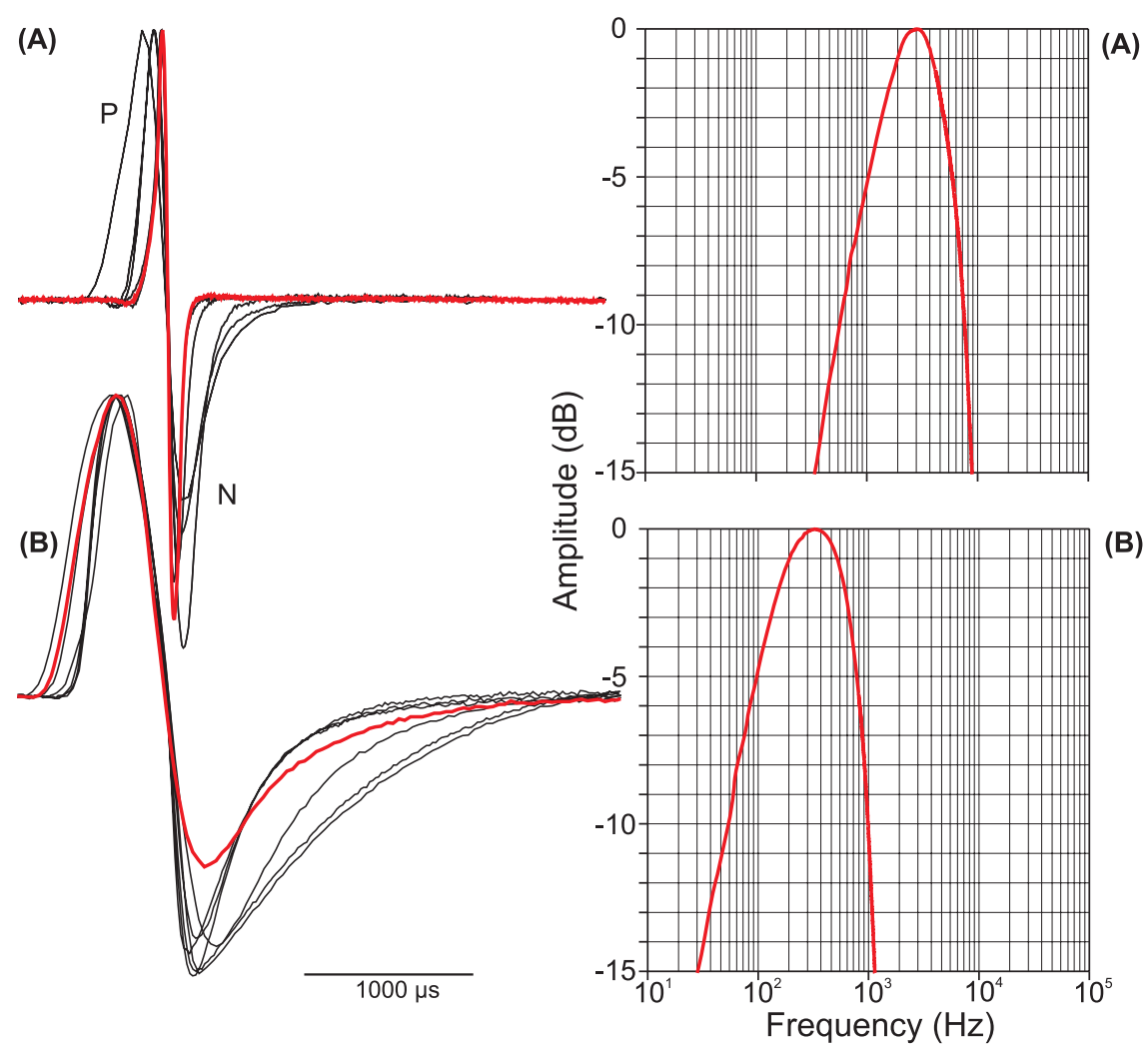

Figure 1. Waveforms of the playback EODs, field-recorded from male M. altisambesi during the breeding season and resampled for stimulation experiments with DAM (Kramer, 1997a). Upper panel, all 'short' pulses superimposed; lower panel, 'long' pulses (as defined for Test series I). All EODs normalised to $+1 \mathrm{~V}$ for the head-positive peak amplitude and $25^{\circ} \mathrm{C}$. Same time bar for both graphs. Details, see Table 1. In black: shortest and longest male EOD used for playback stimulation (350 and $3900 \mu \mathrm{s}$ ); right panels, amplitude spectra for the shortest and the longest EOD. Amplitude in $\mathrm{dB}$ re: peak amplitude $=0 \mathrm{~dB}$. Note that the amplitude spectra differ by about one log unit on the frequency scale. This figure is published in colour in the online edition of this journal, that can be accessed via http://www.brill.nl/beh

of sperm (confirmed by gonad histology; Kramer, 1997a,b). The 12 males differed naturally in EOD pulse duration from 350 to $3900 \mu \mathrm{s}$ (Figure 1, Table 1). The shortest male EOD pulse was very close to the female average (median \pm semi-interquartile in summer 1994 for females, $349.6 \pm 27.6 \mu \mathrm{s}$, $N=43$ excluding outliers; pulse duration determined at $\pm 5 \%$ threshold criterion; for 'winter' (August-September 1999), female pulse duration was 
Table 1. Pulse duration of playback EODs at $\pm 2 \%$ of the head-positive peak amplitude. All EODs recorded from males in the field during the wet breeding season.

\begin{tabular}{lcccccc}
\hline & \multicolumn{2}{c}{ Long EOD } & & \multicolumn{3}{c}{ Short EOD } \\
\cline { 1 - 2 } \cline { 5 - 6 } Field ID & SL $(\mathrm{mm})$ & EOD duration $(\mu \mathrm{s})$ & & Field ID & SL $(\mathrm{mm})$ & EOD duration $(\mu \mathrm{s})$ \\
\hline L10isi & 153 & 3900 & & L09isi & 159 & 1420 \\
L05isi & 144 & 3570 & & L48isi & 136 & 1070 \\
L39isi & 176 & 3440 & & L18isi & 144 & 760 \\
L19isi & 151 & 3170 & & N95ka & 142 & 480 \\
L20isi & 161 & 2690 & & N54ka & 128 & 370 \\
L35isi & 183 & 2470 & & L15isi & 145 & 350 \\
\hline
\end{tabular}

Field IDs taken from Kramer (1997a) and Kramer et al. (2007). isi, originating from Namibia, East Caprivi, Upper Zambezi River at Lisikili, $17^{\circ} 33^{\prime} \mathrm{S}, 24^{\circ} 29^{\prime} \mathrm{E}$; ka, originating from Namibia, East Caprivi, Kwando River at Nakatwa, $18^{\circ} 06^{\prime} \mathrm{S}, 23^{\circ} 23^{\prime} \mathrm{E}$.

$340.2 \pm 19.9 \mu \mathrm{s}, N=22$, different specimens, all specimens field-recorded direct after capture). In August-September the ovaries of females held undeveloped oocytes of up to stage III and were unfit for reproduction, and the testes held no sperm (Kramer, 1997b). The longest female EOD duration in summer, excluding outliers, was $450 \mu \mathrm{s}(N=43)$; the longest outlier EOD, $863 \mu$ s for $N=47$. The longest female winter EOD had a duration of $410.3 \mu$ s ( $N=22$; Kramer et al., 2007).

\section{EOD playback}

The shortest male EOD pulse used for playback stimulation of female experimental subjects (Table 1) had its spectral peak amplitude at $3.07 \mathrm{kHz}$ vs. $0.32 \mathrm{kHz}$ for the longest male playback. The $-10 \mathrm{~dB}$ cutoff frequencies on the spectral high-frequency side were $7.78 \mathrm{kHz}$ and $0.99 \mathrm{kHz}$ for the shortest and the longest male EOD, respectively (Figure 1).

The 12 EODs of these males were normalized to the same peak amplitude, re-sampled at $500 \mathrm{kHz}$ and 8-bit vertical resolution to meet the technical requirements of the DAM, a custom-built, programmable digital-to-analogue converter with memory (Kramer \& Weymann, 1987). EOD waveforms were uploaded into DAM memory that generated bipolar analogue pulse waveforms for stimulation of experimental subjects via dipole fish decoys (Figure 2). 


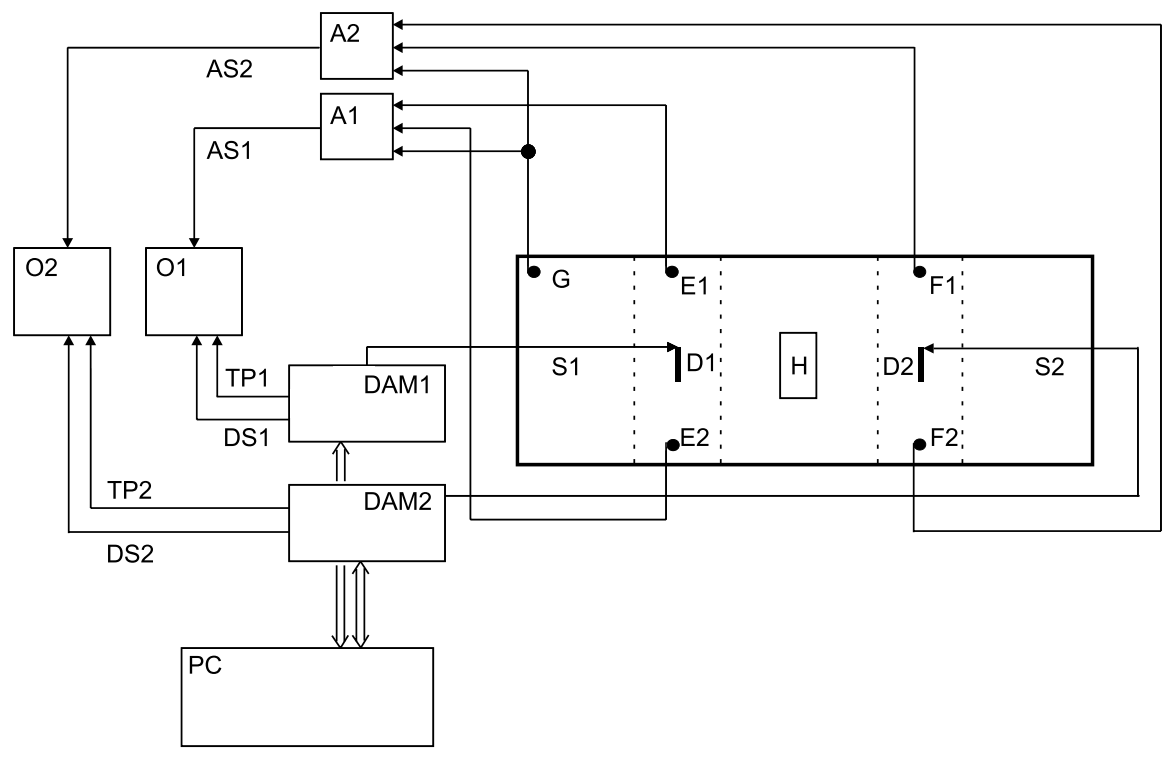

Figure 2. Experimental setup for playback tests. E1 and E2, F1 and F2, recording electrode pairs; G, grounding electrode; A1, A2, differential pre-amplifier; AS1, AS2, amplified signals; O1, O2, oscilloscopes; DAM1, DAM2, digital-to-analogue converters; PC, personal computer; D1, D2, stimulus dipoles that generate electric fields approximating natural fish fields in strength and geometry. Areas between stippled lines, defined as 'close to' or 'near' dipole; H, porous pot shelter in the centre; TP1, TP2, external trigger pulses; S1, S2, DS1, DS2, playback pulse output.

Dipole fish decoys were arranged symmetrically to the left and right of an experimental subject's hiding place, a porous pot. The dipoles were separated from the porous pot by $30 \mathrm{~cm}$. Field intensity within the porous pot, as generated by either dipole, was $300 \mu \mathrm{V} / \mathrm{cm}$ to match the natural stimulus amplitude as generated by a live fish. Field intensity at a mute dipole, as generated by the opposite dipole, was $50 \mu \mathrm{V} / \mathrm{cm}$ (60 $\mathrm{cm}$ distance). Horizontal field intensity was measured using a vertically held measuring dipole made from a pair of 1-mm diameter rods of glassy carbon of $6 \mathrm{~cm}$ length (Sigradur G, HTW, Thierhaupten, Germany), arranged in parallel at $10 \mathrm{~mm}$ separation (centre-to-centre). The rods were insulated except for the lowest $3 \mathrm{~mm}$. Local maximum field intensity was found by rotating the dipole.

Dipoles for playback stimulation were made from a pair of $10 \mathrm{~mm}$ long graphite rods of $5 \mathrm{~mm}$ diameter and $3 \mathrm{~cm}$ separation mounted vertically on a horizontally orientated length of Plexiglas piping held on the aquarium floor by suckers. 
Each dipole was driven by one DAM, and both DAM-dipole units were controlled by the same PC. The DAMs presented the playback EOD at one out of four natural discharge rhythms as recorded from four different males during their nocturnal time of activity, when moving slowly around their aquarium. We recorded the EODs with two electrode pairs orientated at an angle, and a two-channel differential amplifier (GVI2, Electronics workshop, University of Regensburg). The separate output signals were A/D-converted at a sampling rate of $50 \mathrm{kHz}$ on two separate channels (Hydra Light process computer with H109 ADC module, Kinzinger Systeme, Rastadt, Germany), and saved on the hard disk of a personal computer. Inter-discharge interval (IDI) lists were generated using the program package Diadem 8.1/9 (National Instruments, Austin, TX, USA) and the data transformed to meet the data format of the DAM by a program in QuickBasic.

The duration of each playback IDI pattern was $60 \mathrm{~s}$. IDI histograms showed a single mode at $33 \mathrm{~ms}$, with $95 \%$ of IDIs comprised between 15 and $55 \mathrm{~ms}$; mean pulse rate was about $35 \mathrm{~Hz}$ (Figure 3). There were no abrupt changes in IDI duration or breaks, such as observed during agonistic behaviour, that could excite a receiver fish (Kramer, 1979; Machnik \& Kramer, 2008b). Before starting a playback test, each experimental subject was allowed to acclimatize for at least two days. Tests were made at night.

The protocol of Test series I differed from series II by the way playback pulse pairs were formed. In Test series I the six playback EODs of shorter than $2270 \mu$ s were considered 'short' (because they were less than or equal to half the maximum elongation seen during the breeding season). The six playback EODs of greater than $2270 \mu$ s were considered 'long'. For playback, each 'short' pulse was combined with each 'long' pulse, and each combination was tested only once with an experimental subject. A test series, thus, consisted of 36 tests per experimental subject. We used two IDI patterns (patterns A and B of Figure 3). The combination of pulse pair, IDI pattern, the roles of right and left stimulus dipoles were determined following a randomised blocks design (Cochran \& Cox, 1957) in order to guard against the possibility of sidedness. A rest period of $10 \mathrm{~min}$ between tests and no more than 12 tests per day proved adequate to prevent habituation.

Playback pulse pairs in Test series II were formed in order to contrast the shortest pulse with each one of the 11 longer pulses. From 11 pulse pairs, two sides, and two IDI patterns (Figure 3C, D) resulted 44 permutations, and we performed 44 tests per test series per experimental subject. The 

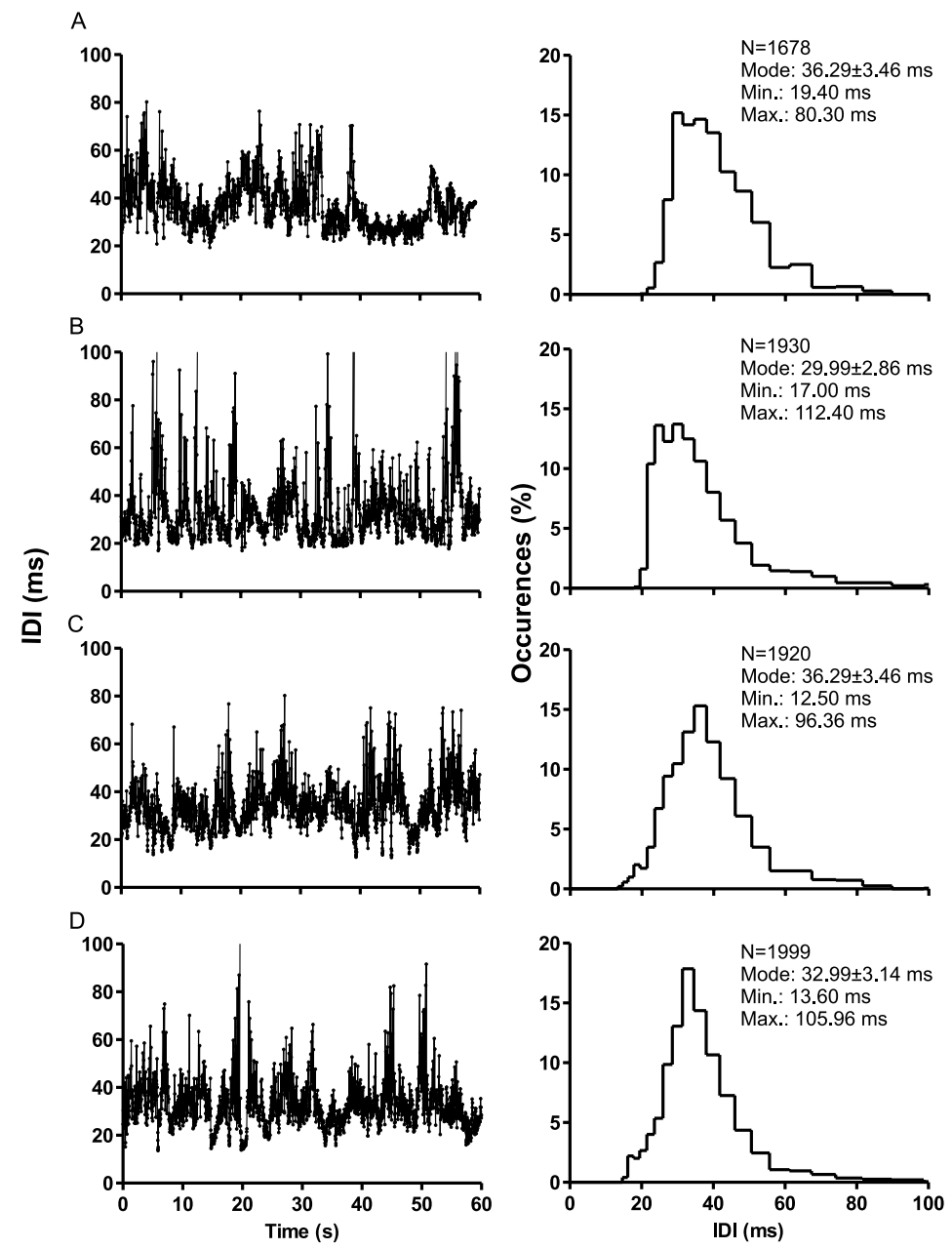

Figure 3. The four samples of inter-discharge interval (IDI) sequences recorded from four different $M$. altisambesi males used for playback presentation of male EODs. Recordings were made at night when isolated fish were quietly swimming about, without abrupt movements nor feeding or foraging behaviours observed during these sections. A and B were used for Test series I in which these males did not form part. C and D, similar recordings from two other males used for Test series II. These males were also used as experimental subjects. Left-hand panels show the sequence of IDIs over time, right-hand panels histograms of the data to their left. Statistical data are means \pm SEM. Average discharge rates for A, $27.97 \mathrm{~Hz}$; B, $32.17 \mathrm{~Hz}$; C, $32.00 \mathrm{~Hz}$; D, $33.32 \mathrm{~Hz}$. 
presentation sequence per test series again followed a randomised blocks design, never using a block twice (Cochran \& Cox, 1957, Table 15.7). We tested each experimental subject 11 times per day, that is, using all stimulus combinations just once, with at least 5 min of rest period between subsequent tests.

Experiments were conducted at night under infrared illumination (Model UF 500 FL, Derwent Systems, Cramlington, UK, spectral emission $\lambda \geqslant$ $800 \mathrm{~nm}$ ). We recorded the fishes' behaviour on video tape, using an infrared camera (model FK6990B-IQ, Cohu, San Diego, CA, USA with zoom lens Cosmicar 1.0: 8-48 mm, Pentax, Tokyo, Japan) and a Hifi S-VHS video tape machine (Panasonic AG-7330, Matsushita Electric Industrial, Osaka, Japan). A pulse marker that was triggered 1:1 by the stimulus pulses generated short blanks on the concomitant video image line, allowing (by their position and separation from neighbouring blanks) for the synchronisation of video images with electrical stimulation records stored on the audio tracks of the video tape. A curtain blocked the experimental subject's view of the experimenter and of any manipulations of the equipment.

We recorded and quantified these behaviours:

(1) Head butt as (a) acceleration towards the active dipole with frontal collision; (b) lateral head butt in a fish passing by a dipole.

(2) Circling around or closely above a dipole $\left(360^{\circ}=1\right.$ circle $)$.

(3) Association time: total time spent within an 20-cm-wide area centred on an active dipole, with at least $50 \%$ of the length of the body within the area specified.

We observed many spawning events and special postures in M. pongolensis, and we reared young ones (for example, Werneyer \& Kramer, 2005; then referred to as 'Marcusenius macrolepidotus South African form'; present species name by resurrection by Kramer et al., 2007). When a female repeatedly visited a male that did not or only weakly retaliate, female aggression preceded courtship. We observed very similar behaviour patterns and partner relationships in M. altisambesi (Lamml \& Kramer, 2007; then referred to as 'Marcusenius macrolepidotus Upper Zambezi form'; new species name 'altisambesi' designated by Kramer et al., 2007).

EOD waveform changes induced by social contact

An additional test series consisted in keeping three individuals per tank whose sensory contact with each other was manipulated. We recorded EOD 
waveforms from 18 individuals in six tanks on 3-5 days per week between 9:00 and 10:00 am, and measured EOD pulse duration as detailed above. In mormyrid fish, diurnal changes of EOD waveform are unknown, and not present in this species. Mormyrid EOD waveforms are extremely stable over extended periods of time (Kramer \& Westby, 1985; Bratton \& Kramer, 1988; Crawford, 1991). The tests were conducted from January 2007 to June 2007.

\section{Statistics}

We used an $\alpha \leqslant 0.05$, two-sided test, and statistical packages StatView v 5.0 and GraphPad Prism v 4.0. In Test series I we kept the results for experimental subjects separate but this proved unnecessary in Test series II the results of which were more homogeneous. In Test series II the average of the four repetitions for each pulse pair and experimental subject were entered in the analysis as $N=1$.

\section{Results}

Playback tests

All experimental subjects responded to the onset of playback by leaving their shelter and swimming up to one of the two 'active' stimulus dipoles. When prior to a test the dipoles had been disconnected from the stimulus generators (the two DAMs), the fish did not respond, even though the experimenter went through all routine manipulations like switching on equipment, typing commands on the PC keyboard etc., in frequent blind tests.

We were unable to discern qualitative differences in behavioural responses between males and females. Both sexes showed frequent headbutting against and circling around the dipoles.

\section{Test series I}

Preference tests in males. Three out of the seven male experimental subjects spent significantly more time 'close' (as defined in Figure 2) to a dipole playing back short rather than long pulses, whereas one male (M3) showed the opposite preference (Figure 4A). This male M3 did not differentiate in any additional behaviour variable, neither in the rate of Head butts nor in the rate of circling (see below). None of the remaining experimental subjects 
showed any preference regarding association time $(p>0.05)$. Four males showed greater rates of aggression, measured as the frequency of head butts, against a dipole playing back short rather than long EODs (Figure 4C), while there was no preference observed in the remaining experimental subjects. Similarly, a dipole playing back short pulses evoked a greater frequency of 'circling' in the single male where there was a significant difference (M5, Figure 4E). Male M5 had shown a preference for short pulses in all three tests, whereas males M2 and M4 had done so in two tests (for statistical data, see Table A1).

None of the experimental subjects showed a preference for one of the two IDI patterns, as measured by 'Time close to dipole' (Chi-squared test, $\chi^{2}<2.455, N=36, p>0.117$ ), nor was there any dependency of the frequency of first choices on playback pulse duration (Chi-squared test, $\chi^{2}<$ 3.457, $N=36, p>0.063$ ).

Preference tests in females. Three females attacked a dipole presenting 'long' pulses more frequently than short ones (Figure 4D) whereas there was no significant difference in the three other females. This is the opposite response to the four males that differentiated. Four out of the six female experimental subjects spent significantly more time 'close' to a dipole playing back long rather than short pulses, that is, we obtained the opposite response shown by the majority of the males that differentiated (three males vs. one male) (Figure 4B). The other females did not show any preference. Four females showed greater 'rates of circling around a dipole' when playing back long pulses (Figure 4F), with no significant response difference in the two remaining females (for statistical data, see Table A1). The single male that differentiated in 'circling' behaviour had responded in the opposite direction.

As in males, none of the females preferred one of the two IDI patterns over the other (Chi-squared test, $\chi^{2}<0.533, N=36, p>0.465$ ). Experimental subjects F1 and F3 significantly preferred the 'right' dipole over the 'left' one for no apparent reason. Because of the balanced randomized blocks design, this sidedness did not bias results regarding preference of waveforms. Three females (F4, F5 and F6) showed their preference for long pulses also by a higher frequency of first choices (Chi-squared test, $\chi^{2}<5.444, N=$ $36, p<0.02$ ), whereas the other females did not differentiate.

\section{Test series II}

We tested the question of whether or not there was a quantitative dependency of choice behaviour on stimulus pulse duration, as had been observed in 

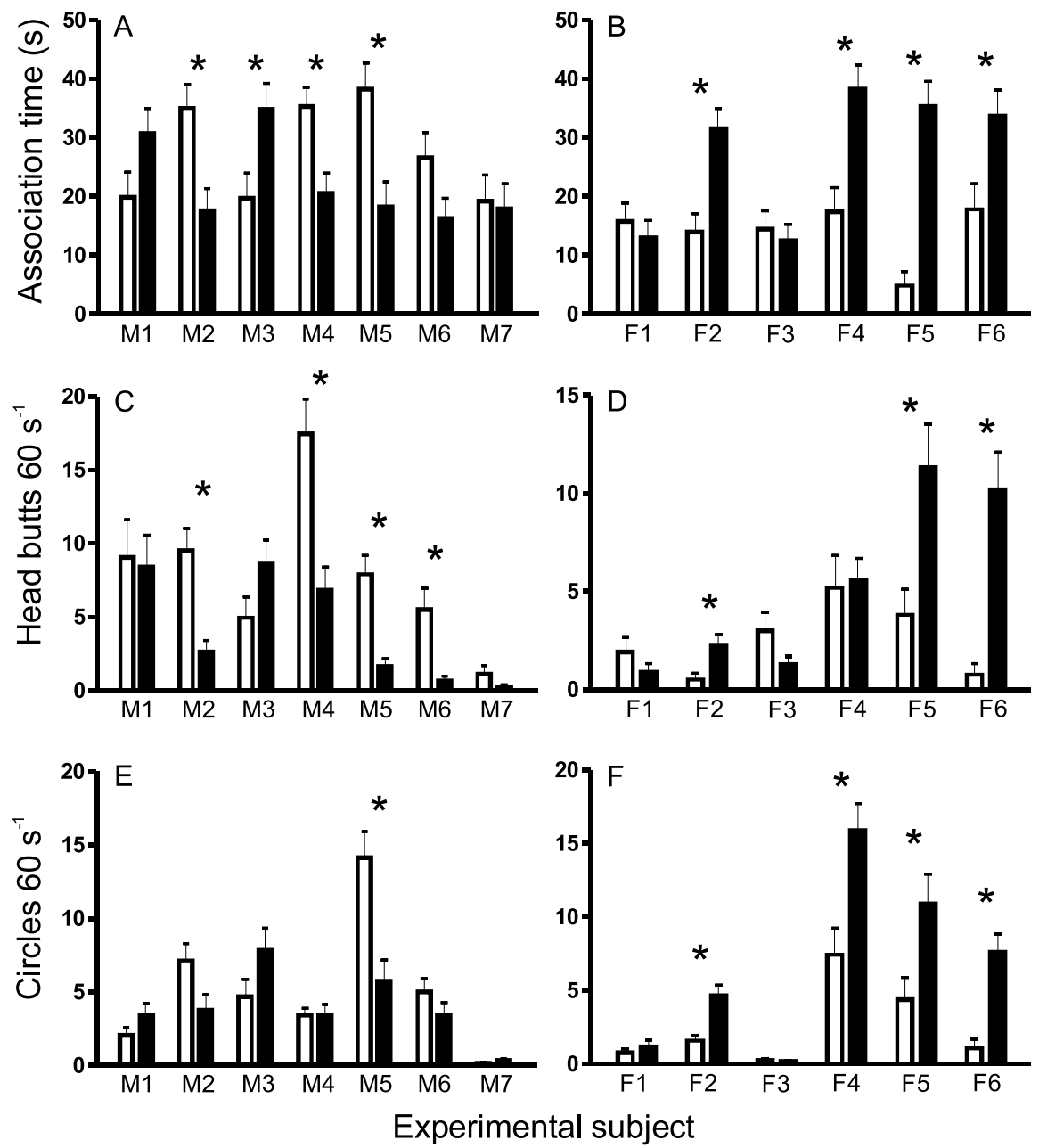

Figure 4. Behaviour of M. altisambesi experimental subjects, evoked by simultaneous playback of a 'long' and a 'short' EOD via two dipoles (for $60 \mathrm{~s}$ per trial). Left-hand panels, male experimental subjects (M1-M7); right-hand panels, females (F1-F6). White bars, behaviour scores for short playback pulses; black bars, long pulses. Asterisks indicate significant differences between pairs of bars $(p<0.05)$. (A, B) Association time measured as time 'near' dipoles given as means + SEM. Note preference (longer times near dipole) for long pulses in four females and one male, and for short pulses in three males. (C, D) As A and B, but for aggression measured as head butts/60 s. Note more aggression (greater frequency of head butts) against dipole presenting long pulses in three females, and against dipole presenting short pulses in four males. (E, F) As A and B, but for circling behaviour. Note the higher frequency of circling around dipole presenting long pulses in four females, and around dipole presenting short pulses in one male. 
M. pongolensis females stimulated with male pulses (Machnik \& Kramer, 2008a,b). Therefore, in playback pulse pairs the shortest pulse of $350 \mu \mathrm{s}$ (that was present in each pair) was contrasted with each one of 11 longer ones.

In the present study on $M$. altisambesi, the most frequent behaviour evoked by playback was aggression. Males from both origins (Upper Zambezi and Okavango) were generally more aggressive than females. In pulse pairs of up to about $1070 \mu$ s difference in duration ( $\Delta$ EODduration), no clear dependency of aggression on pulse duration emerged; the sign of non-significant differences between the scores for both pulses (the short and the longer one) varied widely among experimental subjects. However, from about $2120 \mu \mathrm{s} \Delta$ EODduration on there was a significant tendency for the shorter pulse to evoke more aggression. This was observed in both sexes and in fish from both origins (Figure 5A-D). The longer the 'long' pulse the more ineffective it appeared in evoking aggression; that is, $\Delta$ HeadButts decreased significantly with $\Delta$ EODduration (least-squares linear regression for Upper Zambezi males: $\Delta$ HeadButts $=-0.0071 \times$ $\Delta$ EODduration $+5.58, r^{2}=0.4561, F_{1,75}=62.90, p<0.0001$; Upper Zambezi females: $\Delta$ HeadButts $=-0.0029 \times \Delta$ EODduration -0.27 , $r^{2}=0.1533, F_{1,108}=19.55, p<0.0001$; Okavango males: $\Delta$ HeadButts $=$ $-0.0039 \times \Delta$ EODduration $+1.45, r^{2}=0.1883, F_{1,75}=17.40, p<0.0001$; Okavango females: $\Delta$ HeadButts $=-0.0021 \times \Delta$ EODduration +0.33 , $\left.r^{2}=0.1891, F_{1,108}=25.19, p<0.0001\right)$.

A better fit than with a straight line (linear model) was achieved with a non-linear model, a plateau followed by one phase decay (Figure 6). A better fit of the non-linear model is supported by: (1) a lower sum-of-squares (SS) for the non-linear model (Table 2), (2) a greater $R^{2}$ for the non-linear model than $r^{2}$ for the linear model, (3) no systematic deviation from the non-linear model (replicates test, $p \geqslant 0.1539$; Table 2).

The scores for association time, the time the experimental subjects spent 'close' to an active dipole, plotted against $\triangle$ EODduration, were largely parallel to the ones for aggression (Figure 7 is graphically similar to Figure 5). Starting from about $2120 \mu \mathrm{s}$, the greater $\Delta$ EODduration, the more ineffective the longer pulse in a pair proved to attract the experimental subjects. As with $\Delta$ HeadButts, $\Delta$ AssociationTime decreased significantly with $\triangle$ EODduration (least-squares linear regression for Upper Zambezi males: $\Delta$ AssociationTime $=-0.0134 \times \Delta$ EODduration +11.05 , 


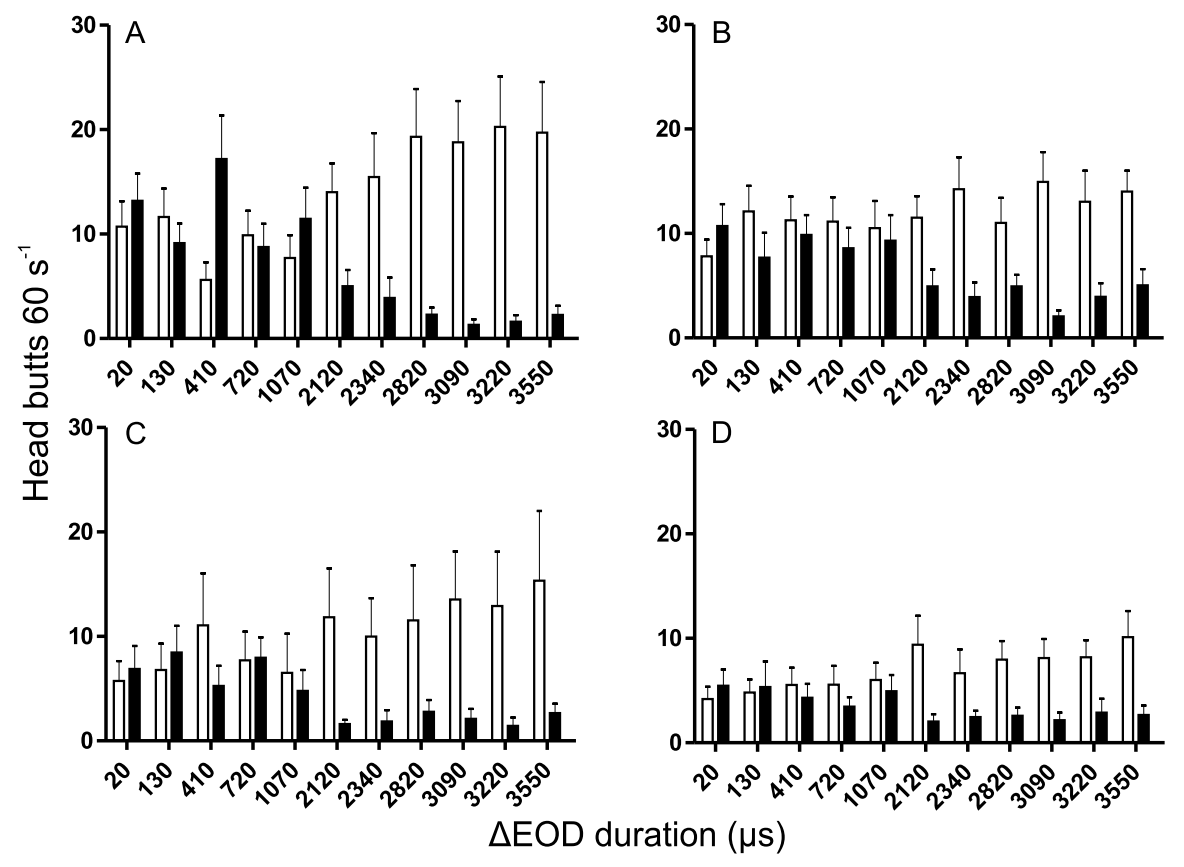

Figure 5. Test series II. Aggression against electric fish dummies, measured as Head Butts/60 s, evoked by EOD playback. Abscissae, difference in playback pulse-pair duration in $\mu \mathrm{s}$. White bars, scores + SEM for short pulse $(350 \mu \mathrm{s})$; black bars, scores + SEM for one out of 11 longer pulses. (A) Upper Zambezi males $(N=7)$; (B) Upper Zambezi females $(N=10)$; (C) Okavango males $(N=7)$; (D) Okavango females $(N=10)$. Note the tendency for increasing difference between paired bars on the right side of graphs.

$r^{2}=0.5278, F_{1,75}=83.82, p<0.0001$; Upper Zambezi females: $\Delta$ AssociationTime $=-0.0047 \times \Delta$ EODduration $-1.27, r^{2}=0.0712$, $F_{1,108}=8.28, p<0.0048$; Okavango males: $\Delta$ AssociationTime $=$ $-0.0091 \times \Delta$ EODduration $+4.89, r^{2}=0.2667, F_{1,75}=27.28, p<0.0001$; Okavango females: $\Delta$ AssociationTime $=-0.0057 \times \Delta$ EODduration +2.17 , $\left.r^{2}=0.1560, F_{1,108}=19.96, p<0.0001\right)$.

A non-linear model, a plateau followed by one phase decay, gave a better fit than the straight line model for the Okavango specimens (both sexes) and the Upper Zambezi males (Table 2, Figure 7A, C, D). For Upper Zambezi females (Figure 7B) the non-linear model did not converge, and the linear model appeared acceptable since the data did not deviate systematically from a straight line (runs test, $p=0.7381$ ). 


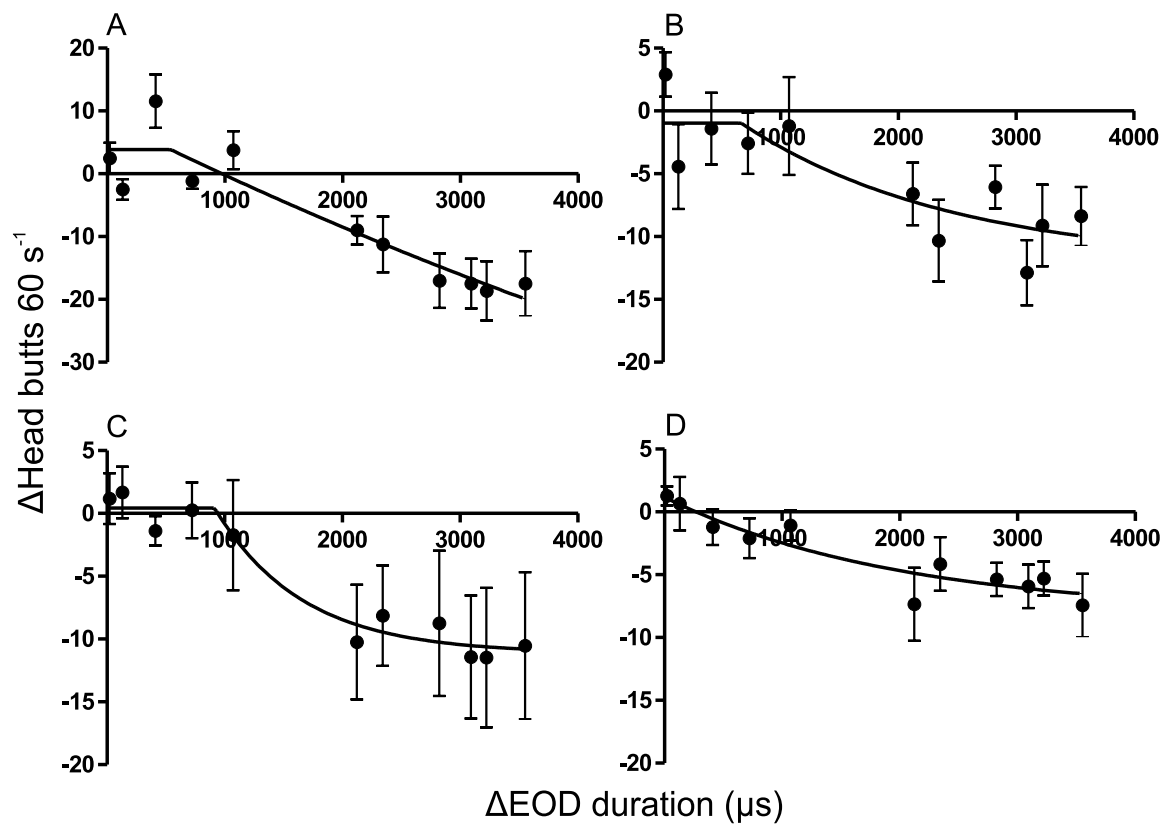

Figure 6. Alternative view of Figure 5, shown as least-squares non-linear regression between $\Delta$ HeadButts $/ 60 \mathrm{~s}$ and $\Delta$ EODduration in $\mu \mathrm{s}$. Data points represent means $\pm 1 \mathrm{SEM}$. Non-linear model 'plateau followed by one phase decay' yields better fit than linear model 'straight line' (Table 2).

The scores for circling differed from those for aggression in their greater inter-individual variation. Some experimental subjects showed very little circling activity although they had shown good attack responses. Similar to the previous results, starting from about $2120 \mu \mathrm{s} \Delta$ EODduration, longer pulses proved increasingly less effective in evoking circling (Figure 8). Therefore, $\Delta$ Circling fell significantly with $\Delta$ EODduration (leastsquares linear regression for Upper Zambezi males: $\Delta$ Circling $=-0.0025 \times$ $\Delta$ EODduration $+1.83, r^{2}=0.3021, F_{1,75}=32.46, p<0.0001 ;$ Upper Zambezi females: $\Delta$ Circling $=-0.0006 \times \Delta$ EODduration +0.57 , $r^{2}=0.0432, F_{1,108}=4.876, p=0.0293$; Okavango males: $\Delta$ Circling $=$ $-0.0005 \times \Delta$ EODduration $+0.51, r^{2}=0.1488, F_{1,75}=13.11, p=0.0005$; Okavango females: $\Delta$ Circling $=-0.0009 \times \Delta$ EODduration $+0.70, r^{2}=$ $\left.0.1784, F_{1,108}=23.46, p<0.0001\right)$.

For Upper Zambezi males and Okavango males and females the nonlinear model gave a better fit than the linear one (Table 2). As already 
Table 2. The decrease of $\Delta$ Response with $\Delta$ EODduration in Test series II, as shown in Fig. 6.

\begin{tabular}{|c|c|c|c|c|c|c|c|}
\hline & \multicolumn{4}{|c|}{ Linear regression } & \multirow{2}{*}{\multicolumn{3}{|c|}{$\begin{array}{c}\text { Non-linear regression } \\
\text { Goodness-of-fit }\end{array}$}} \\
\hline & \multicolumn{3}{|c|}{ Goodness-of-fit } & \multirow[t]{2}{*}{$p$} & & & \\
\hline & $r^{2}$ & SS & $p_{\text {runs }}$ & & $R^{2}$ & SS & $p_{\text {replicates }}$ \\
\hline \multicolumn{8}{|l|}{$\Delta$ HeadButts } \\
\hline Upper-Zambezi-ơ & 0.4561 & 7446 & 0.6061 & $<0.0001$ & 0.4779 & 7148 & 0.1539 \\
\hline Upper-Zambezi-q & 0.1533 & 8391 & 0.9762 & $<0.0001$ & 0.1547 & 8377 & 0.3413 \\
\hline Okavango- $\sigma^{x}$ & 0.1883 & 8258 & 0.9113 & $<0.0001$ & 0.1949 & 8191 & 0.9978 \\
\hline Okavango-o & 0.1891 & 3476 & 0.6061 & $<0.0001$ & 0.1960 & 3446 & 0.8117 \\
\hline \multicolumn{8}{|l|}{$\Delta$ AssociationTime } \\
\hline Upper-Zambezi-ơ & 0.5278 & 20076 & 0.1104 & $<0.0001$ & 0.5812 & 17803 & 0.3510 \\
\hline Upper-Zambezi-q & 0.0712 & 51739 & 0.7381 & 0.0048 & I & I & I \\
\hline Okavango- $\sigma^{x}$ & 0.2667 & 28583 & 0.9113 & $<0.0001$ & 0.2965 & 27421 & 0.9243 \\
\hline Okavango-o & 0.1560 & 31715 & 0.6061 & $<0.0001$ & 0.1668 & 31307 & 0.9899 \\
\hline \multicolumn{8}{|l|}{$\Delta$ Circles } \\
\hline Upper-Zambezi-ơ & 0.3021 & 1840 & 0.9545 & $<0.0001$ & 0.3251 & 1779 & 0.3650 \\
\hline Upper-Zambezi-o & 0.0432 & 1323 & 0.9762 & 0.0293 & / & l & / \\
\hline Okavango- $\sigma^{x}$ & 0.1488 & 161.3 & 0.9113 & 0.0005 & 0.1668 & 157.9 & 0.1873 \\
\hline Okavango-o & 0.1784 & 719.1 & 0.6061 & $<0.0001$ & 0.1924 & 706.9 & 0.6147 \\
\hline
\end{tabular}

Comparison of goodness of fit of linear regression (straight line) with non-linear regression (plateau followed by one phase decay). SS, sum-of-squares; /, non-linear model did not converge. Replicates test for systematical deviation of data from curve, $p \geqslant 0.0867$ in all curves that did converge.

observed with association time, for Upper Zambezi females the non-linear model did not converge.

\section{EOD waveform changes evoked by interaction with neighbours}

In male M. pongolensis sensory contact with male aquarium neighbours that were separated by plastic mesh evoked fights at the mesh border and an elongation of the males' EOD (Hanika \& Kramer, 2008). We designed an experiment for the $M$. altisambesi used in the present study in order to find out whether in M. altisambesi sensory contact with conspecifics would have a similar effect on EOD pulse duration.

In stage I of the 'sensory contact' experiment that lasted two weeks, the three compartments per tank were separated by a pair of solid, opaque and tightly fitting plastic walls that reduced sensory contact between neighbours 


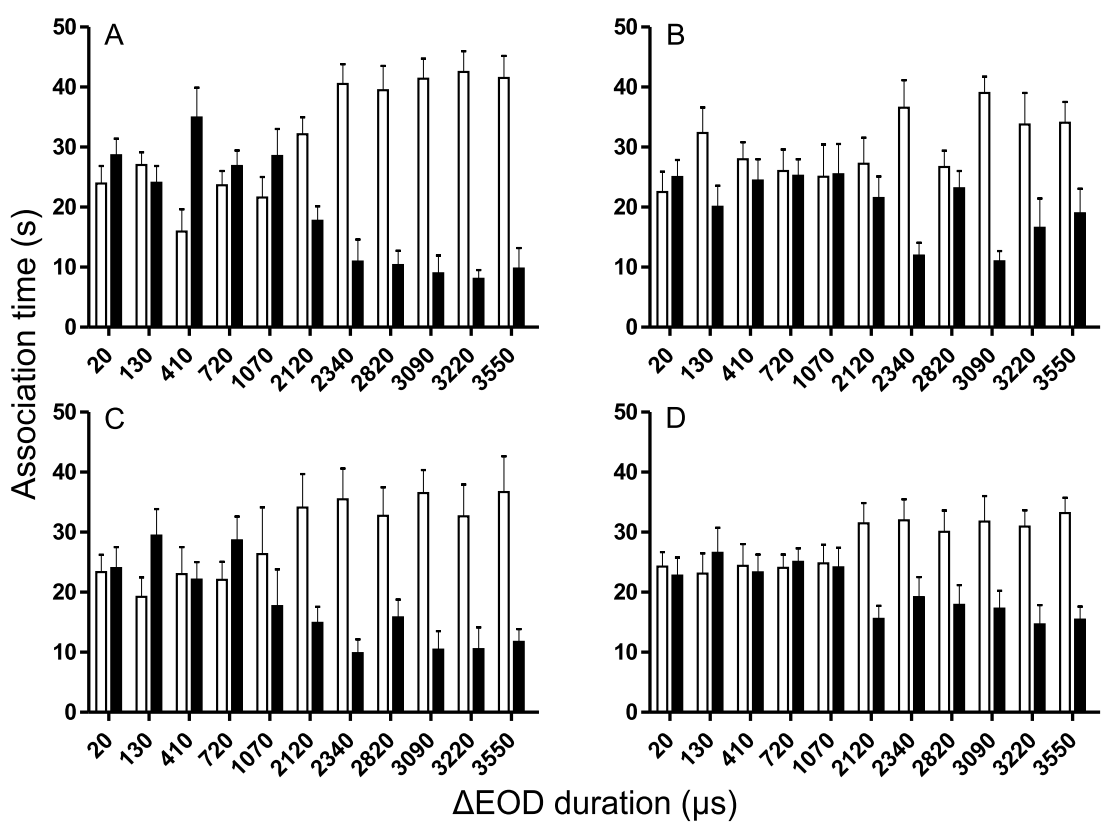

Figure 7. As Figure 5, but for association time with active dipoles.

as much as possible. In stage II the walls were replaced by plastic mesh partitions that allowed unrestricted sensory contact between neighbours, except that they limited mechanical contact to avoid damaging fights. In stage III of the experiment, the solid plastic walls were put back for another week (Figure 9).

There was no clear change of EOD pulse duration in any of the males, neither during nor after the period with plastic mesh. Change was not detected, neither in pure male groups (repeated-measures ANOVA: $F_{2,19}<$ 3.522, $p>0.0800$; Figure 9C) nor when one (repeated-measures ANOVA: $F_{2,19}<3.593, p>0.0770$; Figure 9B) or even two females (repeatedmeasures ANOVA: $F_{2,19}<4.382, p>0.0519$, Figure 9A) were present in a tank. To check for the possibility that the time of sensory contact with neighbours had been too short, we repeated the tests with plastic mesh partitions present, (1) for four weeks (two females, male in centre position: repeated-measures ANOVA: $F_{2,25}<3.219, p>0.0943$ ), and (2) in another trial for 15 weeks (three-male group: repeated-measures ANOVA: $\left.F_{2,73}<2.500, p>0.102\right)$. Even then there were no clear changes of EOD pulse duration, neither during nor after the period with plastic mesh. 


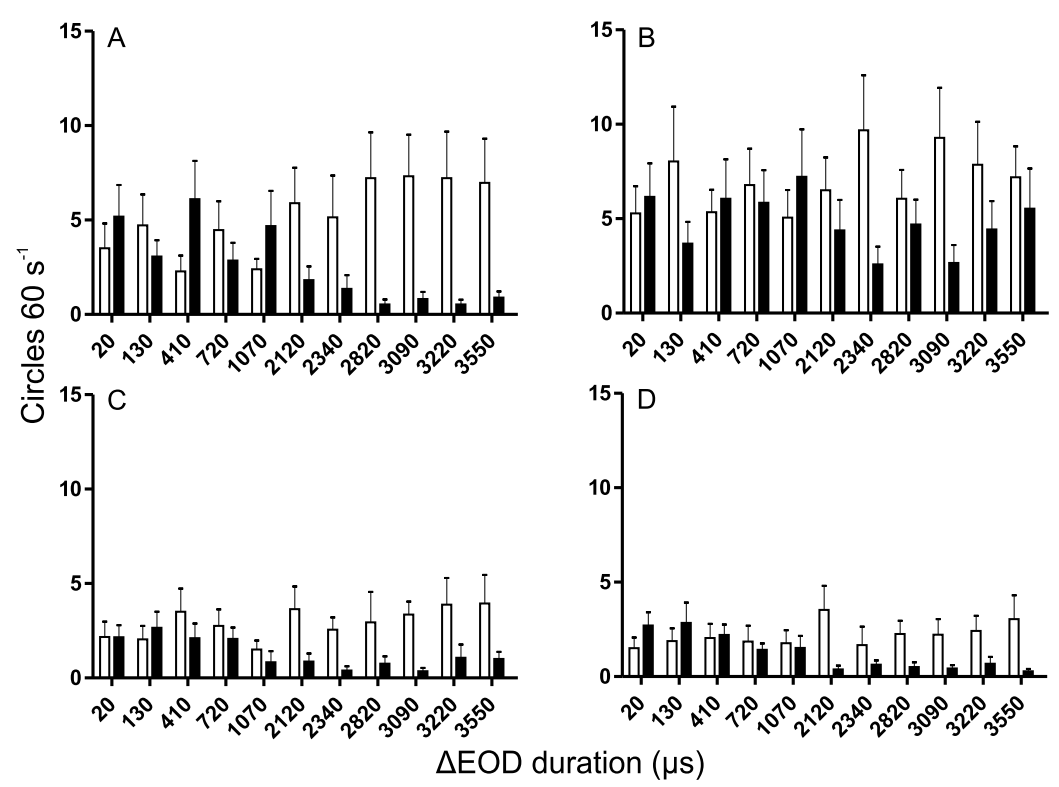

Figure 8. As Figure 5, but for circles/60 s.

\section{Discussion}

\section{Experimental male subjects}

In Test series I and II the experimental M. altisambesi males that differentiated statistically significantly, avoided a fish decoy playing back the long EODs recorded from reproductive males, and preferred to associate with a fish decoy playing back short EODs (exception: male M3 in Test series I for association time). The avoidance of long EODs (or preference of short EODs) was obvious from significantly reduced rates of Head Butts (four of seven males) and a shorter Association Time (three males; the said male M3 gave the opposite response) for long EODs compared with short EODs (Test series I). In Test series II behaviour scores decreased significantly with $\triangle$ EODduration (overall regression); the experimental males showed systematically lower behavioural scores for 'long' pulses when equal to or greater than $2470 \mu \mathrm{s}$ (which agrees well with Test series I where the shortest 'long' EOD was of $2470 \mu$ s duration). There was no difference between the Zambezi and the Okavango specimens.

These males obviously deemed long EODs more threatening than short ones. They have a natural tendency to flock with other individuals of their 

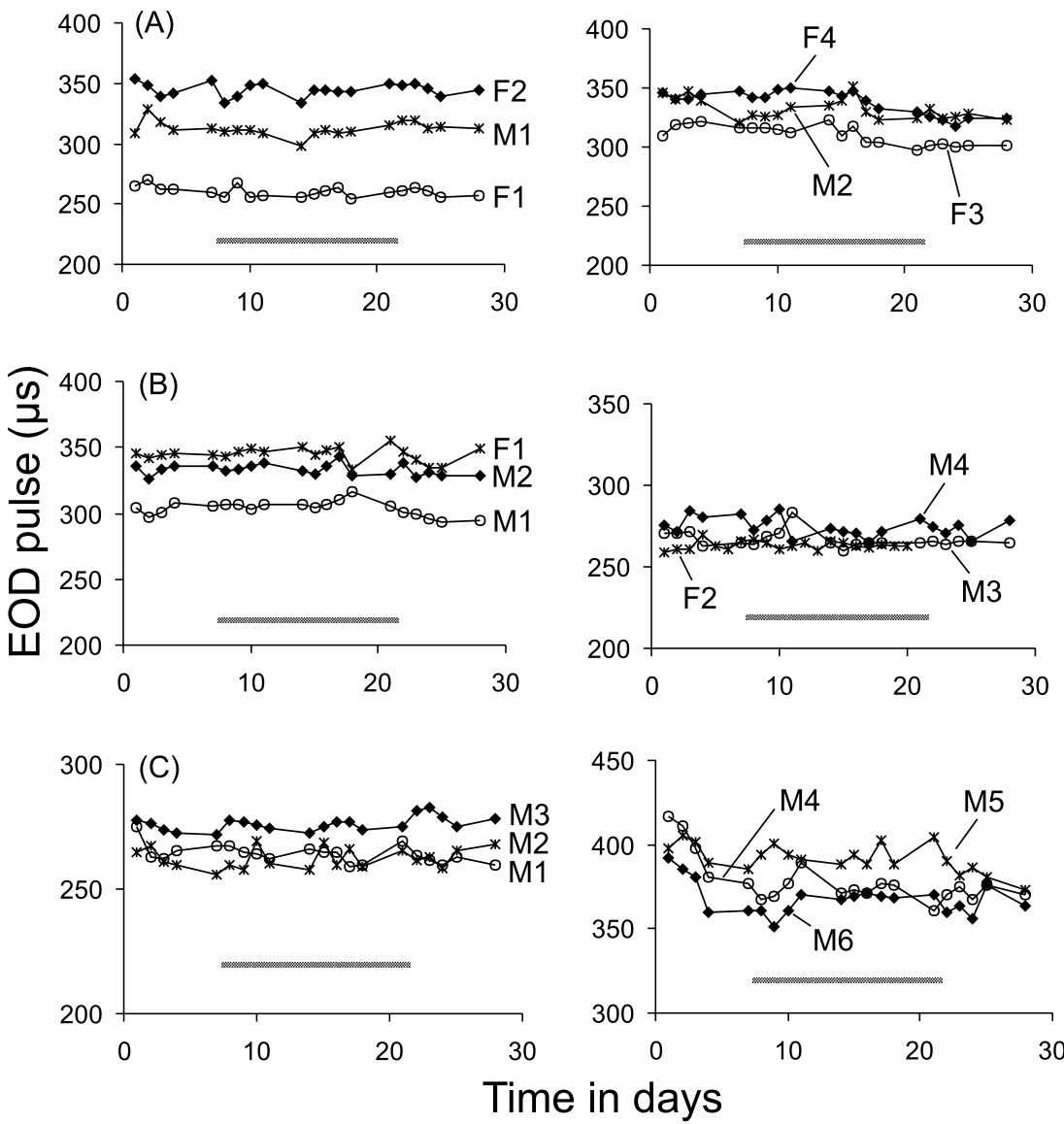

Figure 9. Three-fish-to-a-tank experiments with male and female M. altisambesi, with and without sensory contact. Change of EOD pulse duration of fish in tank (ordinate, $\mu$ s) over time (abscissa, days). Fish were kept in individual compartments separated by solid plastic walls, except for the time marked by a bar when plastic screen mesh afforded unrestricted sensory contact between neighbours (but prevented damaging fights). (A) Two setups, each with two females in the end-compartments and a male in the middle compartment (curve coded by asterisks, see individual legend for each panel). (B) Two setups, each with two males and a female in the middle compartment. (C) Two setups, each with three males per tank. There was no increase of EOD duration evoked by sensory contact in any of the fish.

kind, but apparently not with those that are likely to be aggressive when they themselves are not ready for reproduction and any associated competition.

The long-term experiments with variation of sensory contact of experimental males with live conspecific neighbours did not demonstrate any ef- 
fect on EOD duration for the focal males, even in the 170-day test. This is in contrast to similar studies in M. pongolensis where the presence of male neighbours, when solid plastic walls were replaced by plastic screen mesh, induced marked growth of EOD duration in focal males (Hanika \& Kramer, $2005,2008)$. Both test series of the present study suggest it is difficult or impossible to create a competition situation among $M$. altisambesi males which do not carry a permanent 'status badge' in the form of a long-duration EOD, unlike male M. pongolensis. Therefore, it appears reasonable to assume that M. altisambesi males probably do not compete for status or other resources with other males. We conclude that for the evolution of the long-duration EOD of M. altisambesi males, which is observed only in reproductive season, there is no support for intra-sexual selection, unlike what has been found in M. pongolensis males (Hanika \& Kramer, 2005, 2008).

\section{Experimental female subjects}

Compared with a dipole fish decoy presenting short EODs, four of six experimental females associated with a dipole that displayed long male EODs for a significantly longer time, around which they also circled significantly more often. Three females dealt out significantly more head butts for the 'long EOD' dipole (Test series I). However, in Test series II the experimental females responded similarly to the experimental males: a significant decrease of response scores with playback EOD duration. A systematical response decrease was observed once the 'long' pulse in a pulse pair was equal to or greater than $2470 \mu \mathrm{s}$. As in experimental males, the experimental females from the Zambezi and the Okavango did not show any noticeable difference in response behaviour.

We conclude that in Test series I some of the experimental females must have been in a pre-reproductive hormonal state. This is supported by Lamml \& Kramer's (2007) observation of intense vocalising (sound production in the form of advertisement songs) and courtship behaviour in these same M. altisambesi specimens (same laboratory), observing the same vertical posture a spawning pair of M. pongolensis had shown (Werneyer \& Kramer, 2005). Vocalising, sound production in addition to communicating by EODs, is known to accompany courtship and spawning also in other mormyrids (Crawford et al., 1986; Bratton \& Kramer, 1989; Lamml \& Kramer, 2006; Baier \& Kramer, 2007). By contrast, the experimental females of Test series II must have been in a non-reproductive state more than a year later. 
Therefore, long male EODs were attractive to most experimental females in the first test although none preferred long male EODs in the second. Similar to the experimental males, the experimental females clearly avoided 'long' pulses only when equal to or greater than $2470 \mu$ s (which was the shortest 'long' pulse in test series I). The difference in playback pulse duration appeared to be irrelevant when the 'long' pulse was equal to or less than $1420 \mu \mathrm{s}$ (which was the longest 'short' pulse in Test series I). Apparently, the experimental females did not consider EOD pulses of $1420 \mu$ s duration or less 'long' (i.e., attractive), corresponding well to the steep and dramatic increase of EOD duration when $M$. altisambesi males turn sexually mature (Kramer, 1997a,b). Unlike the situation in M. pongolensis, EODs of all intermediate duration values for the species do not exist, or should they occur, would only be attractive when greater than a high threshold value.

These observations suggest that the long male EOD in M. altisambesi has evolved under female (inter-sexual) selection pressure. Furthermore, Okavango specimens gave responses that were indistinguishable from those of Zambezi specimens, supporting the present taxonomic classification of only one species for both origins (Kramer et al., 2007). The absence of long male EODs in January 2001 (Kramer et al., 2007) that caused concern is most likely due to a delayed flood, hence breeding season. Although January is technically in local 'summer', the flood following rainfall in the Angolan mountains arrives in the Okavango delta region only in April-March (Merron \& Bruton, 1995). Correspondingly, the long male EODs of Zambezi specimens from Caprivi were sampled in March (Kramer, 1997a,b).

\section{Conclusion}

The mating system of M. altisambesi differs markedly from that of M. pongolensis: it appears a sexual dimorphism in male EOD has evolved under female selection pressure (inter-sexual selection) in the former, whereas a weaker form of sex difference in the male EOD has evolved under selection pressure from both sexes (inter- and intra-sexual selection) in the latter (Hanika \& Kramer, 2005, 2008; Machnik \& Kramer, 2008a).

We speculate that sensory bias and sensory exploitation (Basolo, 1990, 1995; Ryan \& Keddy-Hector, 1992) may have initiated a selection cycle for long male pulses: the spectral low-frequency content of long pulses is not only detected by catfish ampullary electroreceptor organs but also by those 
of females, in addition to their high-frequency electroreceptor organs for communication (Knollenorgane). Long pulses may, thus, represent a more effective or attractive stimulus for females. It is usually the stronger stimulus that is preferred by females if there is variation on the population level (Ryan \& Keddy-Hector, 1992). 'Suicidal' male features apparently selected for by female choice are known from many different animals, e.g., certain frogs the mating calls of which attract frog-eating bats (Ryan et al., 1983). The sexually dimorphic EODs of $M$. altisambesi seem to provide a prime example for a male handicap (Zahavi, 1975) where reproductive success is correlated with an exaggerated male trait or ornament, selected for by females, that only the 'best' (healthiest, strongest, parasite-free, etc.) males can afford, indicating 'good genes'.

In $M$. altisambesi there is evidence for selection pressure from electroreceptive catfish predators such as Clarias gariepinus (Merron, 1993; Winemiller \& Kelso-Winemiller, 1994), blocking runaway selection (Fisher, 1930) for male EOD pulse duration to increase even more. In the habitat of M. pongolensis predator pressure from catfish does not seem intense as long as the elongation of male EODs remains moderate (Bruton, 1979).

Apart from predators, the evolutionary plasticity observed in the mating system of the two closely related species of bulldog fish, M. altisambesi and $M$. pongolensis, may be related to ecological differences between the habitats. M. altisambesi is a floodplain species, adapted to spawning on the flooded savannah with unlimited space, where territorial conflicts are probably rare (in local 'winter', thousands or perhaps millions of young ones of the previous season await the next flooding on the savannah to enter the main river; B. Kramer, personal observation). The habitat of M. pongolensis is much more riverine and mountainous where the places suitable for reproduction are probably limited to the river banks and occasional islands.

\section{Acknowledgements}

This paper is dedicated to Professor Dr. h.c. mult. Hubert Markl on the occasion of his $70^{\text {th }}$ birthday. We thank Drs F.H. Van der Bank (University of Johannesburg) and J.S. Engelbrecht (Mpumalanga Parks Board) for permits, for organising sampling trips, and for helping catch and export fish. Ellen Fröhlich and Silvia Förster are thanked for general support and maintenance and care of fish. Katharina Hannig is thanked for assisting in data acquisition for Test series II. Supported by the Deutsche Forschungsgemeinschaft (grants Kr 446/11 and Kr 446/12). 


\section{References}

Baier, B. \& Kramer, B. (2007). Electric communication during courtship and spawning in two sibling species of dwarf stonebasher from southern Africa, Pollimyrus castelnaui and P. marianne (Mormyridae, Teleostei): evidence for a non species-specific communication code? - Behaviour 144: 115-142.

Basolo, A.L. (1990). Female preference predates the evolution of the sword in swordtail fish. - Science 250: 808-810.

Basolo, A.L. (1995). Phylogenetic evidence for the role of a pre-existing bias in sexual selection. - Proc. Roy. Soc. Lond. B Biol. 259: 307-311.

Bratton, B.O. \& Kramer, B. (1988). Intraspecific variability of the pulse-type discharges of the African electric fishes, Pollimyrus isidori and Petrocephalus bovei (Mormyridae, Teleostei), and their dependence on water conductivity. — Exp. Biol. 47: 227-238.

Bratton, B.O. \& Kramer, B. (1989). Patterns of the electric organ discharge during courtship and spawning in the mormyrid Pollimyrus isidori. - Behav. Ecol. Sociobiol. 24: 349368.

Bruton, M.N. (1979). The food and feeding behaviour of Clarias gariepinus (Pisces: Clariidae) in Lake Sibaya, South Africa, with emphasis on its role as a predator of cichlids. — Trans. Zool. Soc. Lond. 35: 47-114.

Bullock, T.H., Hopkins, C.D., Popper, A.N. \& Fay, R.R. (2005). Electroreception. Springer, New York, NY.

Burkhardt, D. \& de la Motte, I. (1988). Big 'antlers' are favoured: female choice in stalk-eyed flies (Diptera, Insecta), field collected harems and laboratory experiments. — J. Comp. Physiol. A 162: 649-652.

Cochran, W.G. \& Cox, G.M. (1957). Experimental designs, 2nd edn. - Wiley, New York, NY.

Crawford, J.D. (1991). Sex recognition by electric cues in a sound-producing mormyrid fish, Pollimyrus isidori. - Brain Behav. Evol. 38: 20-38.

Crawford, J.D., Hagedorn, M. \& Hopkins, C.D. (1986). Acoustic communication in an electric fish, Pollimyrus isidori (Mormyridae). — J. Comp. Physiol. 159: 297-310.

Feulner, P.G.D., Plath, M., Engelmann, J., Kirschbaum, F. \& Tiedemann, R. (2009). Electrifying love: electric fish use species-specific discharge for mate recognition. - Biol. Lett. 5: 225-228.

Fisher, R.A. (1930). The genetical theory of natural selection. - Clarendon Press, Oxford.

Hanika, S. \& Kramer, B. (1999). Electric organ discharges of mormyrid fish as a possible cue for predatory catfish. - Naturwissenschaften 86: 286-288.

Hanika, S. \& Kramer, B. (2000). Electrosensory prey detection in the African sharptooth catfish, Clarias gariepinus (Clariidae), of a weakly electric mormyrid fish, the bulldog (Marcusenius macrolepidotus). — Behav. Ecol. Sociobiol. 48: 218-228.

Hanika, S. \& Kramer, B. (2005). Intra-male variability of its communication signal in the weakly electric fish, Marcusenius macrolepidotus (South African form), and possible functions. - Behaviour 142: 145-166.

Hanika, S. \& Kramer, B. (2008). Plasticity of electric organ discharge waveform in the South African bulldog fish, Marcusenius pongolensis: tradeoff between male attractiveness and predator avoidance? - Front. Zool. 5: 7.

Iles, R.B. (1960). External sexual differences and their significance in Mormyrus kannume Forskål 1775. — Nature 188: 516. 
Kramer, B. (1979). Electric and motor responses of the weakly electric fish Gnathonemus petersii (Mormyridae) to play-back of social signals. — Behav. Ecol. Sociobiol. 6: 6779.

Kramer, B. (1990). Electrocommunication in teleost fishes: behaviour and experiments. Springer, Berlin.

Kramer, B. (1996). Electroreception and communication in fishes. - Gustav Fischer, Stuttgart.

Kramer, B. (1997a). Electric organ discharges and their relation to sex in mormyrid fishes. Naturwissenschaften 84: 119-121.

Kramer, B. (1997b). A field study of African elephantfish (Mormyridae, Teleostei): electric organ discharges in Marcusenius macrolepidotus (Peters, 1852) and Petrocephalus catostoma (Günther, 1866) as related to sex. - J. Afr. Zool. 111: 313-341.

Kramer, B. (2009). Electric communication and electrolocation. - In: Encyclopedia of neuroscience, vol. 5 (Binder, M.D., Hirokawa, N. \& Windhorst, U., eds). Springer, Berlin, p. $1038-1045$.

Kramer, B., Skelton, P.H., van der Bank, F.H. \& Wink, M. (2007). Allopatric differentiation in the Marcusenius macrolepidotus species complex in southern and eastern Africa: the resurrection of $M$. pongolensis and $M$. angolensis, and the description of two new species (Mormyridae, Teleostei). — J. Nat. Hist. 41: 647-708.

Kramer, B. \& Westby, G.W.M. (1985). No sex difference in the waveform of the pulse type electric fish, Gnathonemus petersii (Mormyridae). — Experientia 41: 1530-1531.

Kramer, B. \& Weymann, D. (1987). A microprocessor system for the digital synthesis of pulsed and continuous discharges of electric fish (or animal vocalisations). - Behav. Brain Res. 23: 67-174.

Ladich, F., Collin, S.P., Moller, P. \& Kapoor, B.G. (2006). Communication in fishes. Science Publishers, Enfield, NH.

Lamml, M. \& Kramer, B. (2006). Differentiation of courtship songs in parapatric sibling species of dwarf stonebashers from southern Africa (Mormyridae, Teleostei). - Behaviour 143: 783-810.

Lamml, M. \& Kramer, B. (2007). Allopatric differentiation in the acoustic communication of a weakly electric fish from southern Africa, Marcusenius macrolepidotus (Mormyridae, Teleostei). - Behav. Ecol. Sociobiol. 61: 385-399.

Lissmann, H.W. \& Machin, K.E. (1963). Electric receptors in a non-electric fish (Clarias). - Nature 199: 88-89.

Machnik, P. \& Kramer, B. (2008a). Female choice by electric pulse duration: attractiveness of the males' communication signal assessed by female bulldog fish, Marcusenius pongolensis (Mormyridae, Teleostei). — J. Exp. Biol. 211: 1969-1977.

Machnik, P. \& Kramer, B. (2008b). A male's playback signal turns female Marcusenius pongolensis receivers on or off depending on his behavioural state. - Comm. Integr. Biol. 1: 128-131.

Markowski, B., Baier, B. \& Kramer, B. (2008). Differentiation in electrical pulse waveforms in a pair of sibling Dwarf Stonebashers, Pollimyrus castelnaui and P. marianne: possible mechanisms and functions (Mormyridae, Teleostei). - Behaviour 145: 115-135.

Merron, G.S. (1993). Pack-hunting in two species of catfish, Clarias gariepinus and C. ngamensis in the Okavango Delta, Botswana. - J. Fish Biol. 43: 575-584.

Merron, G.S. \& Bruton, M.N. (1995). Community ecology and conservation of the fishes of the Okavango Delta, Botswana. — Environ. Biol. Fishes 43: 109-119. 
Moller, P. (1995). Electric fishes. History and behaviour. — Chapman \& Hall, London.

Paintner, S. \& Kramer, B. (2003). Electrosensory basis for individual recognition in a weakly electric, mormyrid fish, Pollimyrus adspersus (Günther, 1866). — Behav. Ecol. Sociobiol. 55: 197-208.

Ryan, M.J. \& Keddy-Hector, A. (1992). Directional patterns of female mate choice and the role of sensory biases. - Am. Nat. 139: 4-35.

Ryan, M.J., Tuttle, M.D. \& Barclay, M.R. (1983). Behavioural responses of the frog-eating bat, Trachops cirrhosus, to sonic frequencies. — J. Comp. Physiol. 150: 413-418.

Scheffel, A. \& Kramer, B. (1997). Electrocommunication and social behaviour in Marcusenius senegalensis (Mormyridae, Teleostei). - Ethology 103: 404-420.

Skelton, P. (2001). A complete guide to the freshwater fishes of Southern Africa. - Struik Publishers, Cape Town.

Stoddard, P.K. (1999). Predation enhances complexity in the evolution of electric fish signals. - Nature 400: 254-256.

Werneyer, M. \& Kramer, B. (2002). Intraspecific agonistic interactions in freely swimming mormyrid fish, Marcusenius macrolepidotus (South African form). - J. Ethol. 20: 107121.

Werneyer, M. \& Kramer, B. (2005). Electric signalling and reproductive behaviour in a mormyrid fish, the bulldog Marcusenius macrolepidotus (South African form). J. Ethol. 23: 113-125.

Winemiller, K.O. \& Kelso-Winemiller, L.C. (1994). Comparative ecology of the African pike, Hepsetus odoe, and tigerfish, Hydrocynus forskahlii, in the Zambezi River floodplain. - J. Fish Biol. 45: 211-225.

Zahavi, A. (1975). Mate selection — a selection for handicap. — J. Theor. Biol. 53: 205-214.

\section{Appendix A}

Table A1. Behaviour of experimental subjects (fish ID), evoked by simultaneous playback of pairs of conspecific male EOD pulses, contrasting 'short' and 'long' EODs.

\begin{tabular}{|c|c|c|c|c|c|c|c|c|}
\hline \multirow[t]{2}{*}{ Evoked behaviour } & \multirow{2}{*}{$\begin{array}{l}\text { Fish } \\
\text { ID }\end{array}$} & \multicolumn{3}{|c|}{ Wilcoxon } & \multicolumn{2}{|c|}{ Long EOD } & \multicolumn{2}{|c|}{ Short EOD } \\
\hline & & $p$ (2-sided) & $\begin{array}{c}T^{+}+T^{-} \\
\quad(\mathrm{W})\end{array}$ & $N$ & Mean & SEM & Mean & SEM \\
\hline \multirow[t]{6}{*}{ Association time (s) } & F1 & 0.5691 & -51 & 29 & 13.03 & 2.97 & 15.79 & 3.07 \\
\hline & $\mathrm{F} 2$ & 0.0173 & 304 & 36 & 31.57 & 3.39 & 13.92 & 3.24 \\
\hline & F3 & 0.6878 & -48 & 34 & 12.57 & 2.67 & 14.44 & 3.21 \\
\hline & $\mathrm{F} 4$ & 0.0142 & 312 & 33 & 38.22 & 4.10 & 17.38 & 4.09 \\
\hline & F5 & 0.0001 & 430 & 36 & 35.35 & 4.18 & 4.90 & 2.29 \\
\hline & F6 & 0.0496 & 249 & 36 & 33.64 & 4.44 & 17.81 & 4.34 \\
\hline
\end{tabular}


Table A1. (Continued.)

\begin{tabular}{|c|c|c|c|c|c|c|c|c|}
\hline \multirow[t]{2}{*}{ Evoked behaviour } & \multirow{2}{*}{$\begin{array}{l}\text { Fish } \\
\text { ID }\end{array}$} & \multicolumn{3}{|c|}{ Wilcoxon } & \multicolumn{2}{|c|}{ Long EOD } & \multicolumn{2}{|c|}{ Short EOD } \\
\hline & & $p$ (2-sided) & $\begin{array}{c}T^{+}+T^{-} \\
\quad(\mathrm{W})\end{array}$ & $N$ & Mean & SEM & Mean & SEM \\
\hline & M1 & 0.3536 & 119 & 36 & 30.76 & 4.24 & 19.87 & 4.32 \\
\hline & M2 & 0.0136 & -315 & 36 & 17.64 & 3.73 & 35.11 & 3.94 \\
\hline & M3 & 0.0188 & 287 & 35 & 34.80 & 4.47 & 19.69 & 4.28 \\
\hline & M4 & 0.0419 & -260 & 36 & 20.54 & 3.48 & 35.36 & 3.21 \\
\hline & M5 & 0.0379 & -265 & 36 & 18.33 & 4.17 & 38.31 & 4.35 \\
\hline & M6 & 0.1744 & -153 & 33 & 16.22 & 3.54 & 26.63 & 4.24 \\
\hline & M7 & 0.6037 & -49 & 30 & 18.03 & 4.21 & 19.25 & 4.35 \\
\hline \multirow[t]{13}{*}{ Head butts/60 s } & $\mathrm{F} 1$ & 0.1899 & -61 & 18 & 0.89 & 0.44 & 1.92 & 0.73 \\
\hline & $\mathrm{F} 2$ & 0.0071 & 166 & 22 & 2.25 & 0.57 & 0.50 & 0.33 \\
\hline & F3 & 0.3937 & -57 & 23 & 1.31 & 0.39 & 3.00 & 0.95 \\
\hline & $\mathrm{F} 4$ & 0.4421 & 87 & 33 & 5.58 & 1.10 & 5.19 & 1.64 \\
\hline & F5 & 0.0248 & 241 & 28 & 11.33 & 2.19 & 3.81 & 1.28 \\
\hline & F6 & 0.0001 & 338 & 32 & 10.19 & 1.91 & 0.75 & 0.59 \\
\hline & M1 & 0.9032 & 14 & 32 & 8.39 & 2.20 & 9.06 & 2.53 \\
\hline & M2 & 0.0034 & -344 & 35 & 2.61 & 0.78 & 9.53 & 1.50 \\
\hline & M3 & 0.1552 & 146 & 32 & 8.64 & 1.60 & 4.94 & 1.42 \\
\hline & M4 & 0.0078 & -326 & 35 & 6.83 & 1.57 & 17.47 & 2.34 \\
\hline & M5 & 0.0009 & -424 & 36 & 1.67 & 0.48 & 7.92 & 1.30 \\
\hline & M6 & 0.0040 & -178 & 23 & 0.67 & 0.35 & 5.50 & 1.47 \\
\hline & M7 & 0.1521 & -37 & 11 & 0.22 & 0.14 & 1.14 & 0.59 \\
\hline \multirow[t]{13}{*}{ Circles/60 s } & $\mathrm{F} 1$ & 0.7607 & 17 & 21 & 1.17 & 0.45 & 0.75 & 0.27 \\
\hline & $\mathrm{F} 2$ & 0.0023 & 326 & 32 & 4.67 & 0.67 & 1.61 & 0.35 \\
\hline & F3 & 0.8087 & -5 & 9 & 0.17 & 0.08 & 0.25 & 0.12 \\
\hline & F4 & 0.0280 & 269 & 36 & 15.92 & 1.82 & 7.44 & 1.80 \\
\hline & F5 & 0.0299 & 266 & 28 & 10.92 & 2.01 & 4.39 & 1.53 \\
\hline & F6 & 0.0005 & 305 & 35 & 7.64 & 1.22 & 1.11 & 0.59 \\
\hline & M1 & 0.2547 & 117 & 32 & 3.47 & 0.73 & 2.08 & 0.50 \\
\hline & M2 & 0.0617 & 210 & 34 & 3.78 & 1.03 & 7.17 & 1.13 \\
\hline & M3 & 0.1899 & 161 & 35 & 7.86 & 1.47 & 4.69 & 1.17 \\
\hline & M4 & 0.9145 & -13 & 34 & 3.44 & 0.69 & 3.42 & 0.46 \\
\hline & M5 & 0.0106 & -313 & 36 & 5.78 & 1.41 & 14.14 & 1.80 \\
\hline & M6 & 0.3125 & -104 & 30 & 3.44 & 0.84 & 5.03 & 0.94 \\
\hline & M7 & 0.5311 & 13 & 10 & 0.33 & 0.16 & 0.17 & 0.07 \\
\hline
\end{tabular}

The four right-hand columns give scores and standard errors for each experimental subject separately. $P$ values for significantly different pairs of scores in boldface. $N=36$ for all tests; however, ties are omitted for the Wilcoxon matched-pairs signed-ranks test, which reduces the apparent $N$. 